\title{
An adsorptive bioprocess for production and recovery of resveratrol with Corynebacterium glutamicum
}

\author{
Adelaide Braga, ${ }^{\mathrm{a}, \mathrm{b}^{* *} \odot} \odot$ Marcelo Silva, ${ }^{\mathrm{c} \dagger} \odot$ Joana Oliveira, ${ }^{\mathrm{a}, \mathrm{b}}$ Ana Rita Silva, ${ }^{\mathrm{a}, \mathrm{b}}$ \\ Patrícia Ferreira, ${ }^{\mathrm{a}, \mathrm{b}}$ Marcel Ottens, ${ }^{\mathrm{c}}$ Isabel Rocha ${ }^{\mathrm{a}, \mathrm{b}}$ and Nuno Faria ${ }^{\mathrm{a}, \mathrm{b}}$
}

\begin{abstract}
BACKGROUND: The growing interest in polyphenols has led to the design of industrial-scale processes able to produce them by fermentation and recover them in a more sustainable way. The goal of this work is to present two integrated approaches for the recovery of resveratrol, obtained through fermentation. The production of resveratrol using Corynebacterium glutamicum and its continuous removal using a hydrophobic resin is described. Batch production is compared with in situ product removal, where Amberlite XAD-7HP is either directly added to the medium (direct adsorption) or is present in an external column (external adsorption).
\end{abstract}

RESULTS: For both adsorption strategies tested, the amount of extracellular resveratrol increased from $75 \%$ to at least $90 \%$ of the total amount produced. However, lower total resveratrol concentrations were attained -3.6 and $2.2 \mathrm{mg} \mathrm{L}^{-1}$, for the external and direct contact strategies, respectively, versus $5.3 \mathrm{mg} \mathrm{L}^{-1}$ for batch experiments.

CONCLUSIONS: The proposed in situ removal strategies demonstrated the potential of increasing the excretion of resveratrol produced intracellularly. These process configurations may not only lead to a simpler downstream process design, but also to the avoidance of potential problems with the toxicity of polyphenols to the cells, especially when larger titers are obtained. (c) 2017 Society of Chemical Industry

Keywords: Amberlite XAD7-HP; Corynebacterium glutamicum; direct adsorption; external adsorption; in situ product removal (ISPR); resveratrol

\section{INTRODUCTION}

Polyphenols are secondary metabolites, naturally produced by plants, which have a wide range of applications, such as colorants and nutraceuticals. The molecule resveratrol is one of these compounds, which is speculated to help reducing cardiovascular mortality, lung and prostate cancer, with anti-inflammatory, anti-diabetic, antithrombotic, and anti-aging properties. ${ }^{1}$

Although most commercially available resveratrol is obtained by extraction from plants, such as Polygonum cuspidatum, ${ }^{2}$ there can be several advantages associated with the use of fermentation based processes for its production. Some of the most important ones are the less complex purification process (due to the simpler chemical matrix), the possibility of having more productivity by means of strain genetic engineering and the fact that no large crop areas are needed. The concentration of resveratrol that can be obtained from plant cell cultures is at most equal to that reported as naturally occurring in the plant, being the grape cell suspensions $(V$. vinifera) the most promising one, with a resveratrol yield ranging from $2-5 \mathrm{mg} \mathrm{L}^{-1} .3,4$ The first studies for microbial resveratrol production reported the use of Saccharomyces cerevisiae and Escherichia coli as cell factories, with a production of around $0.5 \mathrm{~g}$ $\mathrm{L}^{-1} .2,5-10$ More recently, other organisms, such as C. glutamicum, which is a workhorse in industrial biotechnology, especially for the production of several aminoacids, ${ }^{11}$ proved to be a promising host organisms for resveratrol production. ${ }^{12,13}$ It is a generally regarded as a safe (GRAS status) microorganism able to achieve high cell densities, ${ }^{14}$ with high resistance to the presence of small aromatic compounds, ${ }^{15}$ able to grow on $p$-coumaric acid, ferulic acid, caffeic acid and 3-(4-hydroxyphenyl)- propionic acid as sole carbon and energy sources. ${ }^{16}$ This bacterium has also already been genetically modified for the synthesis of resveratrol directly from glucose. ${ }^{12,17}$ Corynebacterium glutamicum DelAro ${ }^{4}$ pMKEx2_sts ${ }_{A h}-4 C l_{P C}$ pEKEx3_aroH Ec $_{-} t a l_{F}$ has the shikimate pathway deregulated for overproducing $L$-tyrosine and a heterologous tyrosine ammonia lyase (TAL) for the conversion of $L$-tyrosine to $p$-coumaric acid. Those are key steps for connecting the endogenous amino acid anabolism from glucose to the synthetic polyphenol pathway, ${ }^{12}$

\footnotetext{
* Correspondence to: A Braga, Centre of Biological Engineering, University of Minho, Campus de Gualtar 4710-057, Braga, Portugal. E-mail:abraga@deb.uminho.pt

$\dagger$ These authors contributed equally to this work

a Biotempo, Barco, Guimarães, Portugal

b Centre of Biological Engineering, University of Minho, Braga, Portugal

c Department of Biotechnology, Delft University of Technology, Delft, The Netherlands
} 
(a)

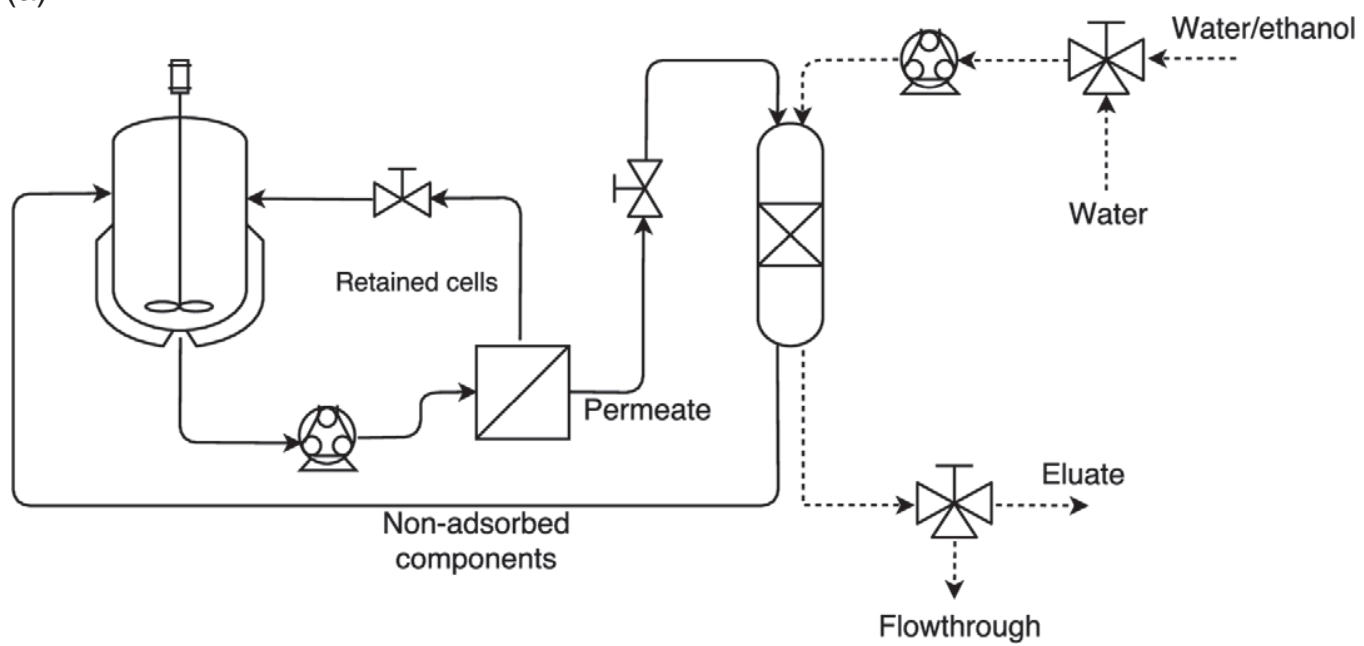

(b)

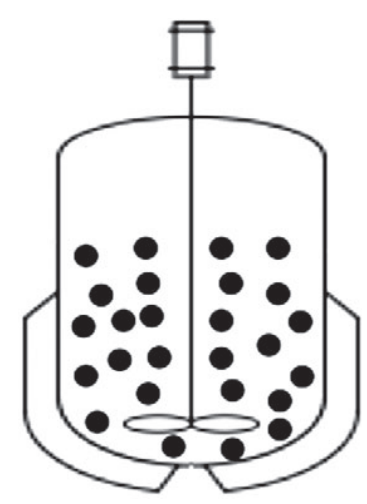

Figure 1. Experimental set-up for the 'External Adsorption' (a) and 'Direct Adsorption' (b) strategies.

avoiding the addition of precursors, which would render the production processes expensive for industrial applications. ${ }^{18,19}$

Although effort is being applied to the pathway engineering in C. glutamicum, improvement of the resveratrol production as a whole - including the downstream process - is essential. It is known that resveratrol stability is dependent on process conditions such as dissolved oxygen, $\mathrm{pH}$, temperature and light. ${ }^{20}$ For example, a temperature higher than $30^{\circ} \mathrm{C}$ seemed to affect the production of resveratrol in E. coli. ${ }^{21}$ Moreover, resveratrol can have a negative effect on cell growth when concentrations are in the $0.5 \mathrm{~g} \mathrm{~L}^{-1}$ range. ${ }^{22}$ All these unwanted effects can be avoided to some extent, by using an in situ product removal strategy. ${ }^{23}$

The goal of this work is to evaluate and compare the performance (in terms of yield, product excretion and process simplicity) of the batch production of resveratrol using C. glutamicum in three scenarios: no product removal, product removal by direct contact with hydrophobic resins (present inside the liquid) and product removal by external adsorption (using an adsorption column).

\section{EXPERIMENTAL PROCEDURES}

\section{Bacterial strain, media and growth conditions}

Corynebacterium glutamicum DelAro ${ }^{4}$ pMKEx2_sts ${ }_{A h}-4 C I_{P C}$ pEKEx3_ $\mathrm{aroH}_{E C-} t_{\mathrm{al}}$ strain was kindly supplied by the Institute of Bioand Geosciences (IBG) (Jülich, Germany) within the scope of the BachBerry project. ${ }^{12}$ It was cultivated aerobically at $30^{\circ} \mathrm{C}$ in Brain Heart Infusion (BHI) medium (only for precultures) or defined CGXII medium with glucose as sole carbon and energy sources. ${ }^{24}$ CGXII medium ( $\mathrm{pH} 7.0)$ contained (per liter) $20 \mathrm{~g}$ of $\left(\mathrm{NH}_{4}\right)_{2} \mathrm{SO}_{4}, 1 \mathrm{~g}$ of $\mathrm{KH}_{2} \mathrm{PO}_{4}, 1 \mathrm{~g}$ of $\mathrm{K}_{2} \mathrm{HPO}_{4}, 0.25 \mathrm{~g}$ of $\mathrm{MgSO}_{4} \times 7 \mathrm{H}_{2} \mathrm{O}, 10 \mathrm{mg}$ of $\mathrm{CaCl}_{2}$, $10 \mathrm{mg}$ of $\mathrm{FeSO}_{4} \times 7 \mathrm{H}_{2} 0,10 \mathrm{mg}$ of $\mathrm{MnSO}_{4} \times \mathrm{H}_{2} \mathrm{O}, 1 \mathrm{mg}$ of $\mathrm{ZnSO}_{4} \times 7 \mathrm{H}_{2} \mathrm{O}$, $0.2 \mathrm{mg}$ of $\mathrm{CuSO}_{4}, 0.02 \mathrm{mg}$ of $\mathrm{NiCl}_{2} \times 6 \mathrm{H}_{2} 0,0.2 \mathrm{mg}$ of biotin, $5 \mathrm{~g}$ of urea, $42 \mathrm{~g}$ of 3-morpholinopropanesulfonic acid (MOPS), $40 \mathrm{~g}$ of glucose, and $30 \mathrm{mg}$ of protocatechuic acid. For plasmid maintenance kanamycin $\left(25 \mathrm{mg} \mathrm{L}^{-1}\right)$ and spectinomycin $\left(100 \mathrm{mg} \mathrm{L}^{-1}\right)$ were added to the medium. In the fermenter experiments, urea and MOPS were omitted as the $\mathrm{pH}$ was automatically controlled.

Corynebacterium glutamicum was cultivated for $8-10 \mathrm{~h}$ in a $500 \mathrm{~mL}$ baffled Erlenmeyer flask containing $50 \mathrm{~mL}$ of BHI medium on a rotary shaker at $200 \mathrm{rpm}$ (first preculture) and was subsequently inoculated into $100 \mathrm{~mL}$ CGXII medium in $1 \mathrm{~L}$ baffled
Erlenmeyer flasks (second preculture). The starting $\mathrm{OD}_{600}$ for the second preculture was 1 . The second preculture was cultivated for $16-17 \mathrm{~h}$ on a rotary shaker at $200 \mathrm{rpm}$ and used to inoculate the fermenter to an initial $\mathrm{OD}_{600}$ of 1 . The heterologous gene expression was induced with $1 \mathrm{mmol} \mathrm{L}^{-1}$ IPTG at a biomass concentration of $2-3 \mathrm{~g} \mathrm{~L}^{-1}$. The fermentation experiments were performed in a 2 L DASGIP ${ }^{\circledR}$ Parallel Bioreactor System for Microbial Applications with 3 simultaneous bioreactors placed on a temperature controlled BioBlock. The operating volume for the fermentations was $1 \mathrm{~L}$, the temperature set-point was maintained at $30^{\circ} \mathrm{C}$, the $\mathrm{pH}$ was automatically controlled at 7 by the addition of $\mathrm{NaOH} 3 \mathrm{~mol}$ $\mathrm{L}^{-1}$ and $\mathrm{HCl} 3 \mathrm{~mol} \mathrm{~L}^{-1}$. The dissolved oxygen was kept above $30 \%$ of saturation by feedback control of the stirring speed from $650 \mathrm{rpm}$ to a maximum of $1500 \mathrm{rpm}$ and air-flow rate of $1 \mathrm{vvm}$. Foam was disrupted by the addition of antifoaming agent, Antifoam 204 (Sigma-Aldrich).

In the external adsorption experiments the bioreactor was connected to a microfiltration unit (Microdyn-Nadir Filter Module MD 020 CP 2 N) in a closed loop. The fermentation broth was pumped through the microfiltration unit using a peristaltic pump at a flow rate of $10 \mathrm{~L} \mathrm{~min}^{-1}$. The retentate from the microfiltration unit was led back to the bioreactor and the cell-free permeate was pumped through the adsorption column (bed dimensions $25 \times 400 \mathrm{~mm}$ ) containing $60 \mathrm{~g}$ of Amberlite XAD-7 HP resin and then fed back into the bioreactor (Fig. 1(a)). It was determined for the XAD-7 HP resin, that with a resveratrol liquid concentration of $5 \mathrm{mg} \mathrm{L}^{-1}$ (value obtained for the batch experiments with no product removal, shown in the Results section), the resin capacity is $5 \mathrm{mg}$ resveratrol g wet ${ }^{-1}$ (shown in the Results section). Assuming that the dynamic binding capacity would be $10 \%$ of the equilibrium binding capacity (adsorption kinetics is not infinitely fast), $10 \mathrm{~g}$ of wet resin would be the minimum quantity needed in the column to bind all the produced compound. For that reason and also to account for a possible production increase using this strategy, $60 \mathrm{~g}$ of resin were used.

In the direct adsorption experiments, Amberlite XAD-7 HP beads were weighed and placed $\left(10 \mathrm{~g} \mathrm{~L}^{-1}\right)$ inside the bioreactor before inoculation (Fig. 1(b)). This solid phase concentration was also chosen for the above-mentioned reasons. 
Table 1. Physical characteristics of the selected resins

\begin{tabular}{lcccccccc} 
Resin & $\begin{array}{c}\text { Dipole } \\
\text { moment }\end{array}$ & Diameter $(\mu \mathrm{m})$ & $\begin{array}{c}\text { Surface } \\
\text { area }\left(\mathrm{m}^{2} \mathrm{~g}_{\mathrm{dry}}{ }^{-1}\right)\end{array}$ & $\begin{array}{c}\text { Wet density } \\
\left(\mathrm{g}_{\text {wet }} \mathrm{mL}^{-1}\right)\end{array}$ & $\begin{array}{c}\text { Wet dry mass } \\
\text { ratio-1 }\end{array}$ & $\begin{array}{c}\text { Skeletal density } \\
\left(\mathrm{g}_{\mathrm{dry}} \mathrm{mL}^{-1}\right)\end{array}$ & $\begin{array}{c}\text { Bulk density } \\
\left(\mathrm{g}_{\mathrm{wet}} \mathrm{mL}^{-1}\right)\end{array}$ & $\begin{array}{c}\text { Porosity } \\
\left(\mathrm{mL} \mathrm{mL}^{-1}\right)\end{array}$ \\
\hline XAD-7HP & 1.8 & 500 & 450 & 1.05 & 2.9 & 1.24 & 630 \\
\hline
\end{tabular}

\section{Adsorption isotherm determination via batch uptake experiments}

The determination of the adsorption isotherms of resveratrol and $p$-coumaric acid was performed by batch uptake experiments, using glass flasks with rubber stops. A stock solution saturated with the compound of interest - either resveratrol or $p$-coumaric acid - was prepared. In the case of resveratrol, the solvent was MilliQ water and for $p$-coumaric acid, the solutions were prepared with $0.1 \mathrm{~mol} \mathrm{~L}^{-1}$ sodium phosphate monobasic buffer at $\mathrm{pH} 7.0$, in order to mimic fermentation conditions (where $\mathrm{pH}$ is controlled at 7.0). Before adsorption took place, the XAD-7HP resin was first washed with MilliQ water, then with ethanol and afterwards equilibrated with the desired solvent.

The flasks were shaken at $525 \mathrm{rpm}$ in an orbital shaker Heidolph Titramax 1000 (Heidolph Instruments GmbH \& Co. KG, Germany) at room temperature $\left(20 \pm 2{ }^{\circ} \mathrm{C}\right)$ for $3 \mathrm{~h}$, in order to achieve equilibrium (adsorption kinetics data not shown). At the end of the experiment, for the case of $p$-coumaric acid, a sample of $1 \mu \mathrm{L}$ was injected in the UHPLC. For the case of resveratrol, when the liquid concentration was expected to be too low, the sample was first concentrated by extraction with butyl acetate (concentration factor was 4 or 5). A sample of $1 \mu \mathrm{L}$ was then taken from the organic phase for UHPLC analysis.

\section{Resin pretreatment}

The resin used during the fermentation experiments was the Amberlite XAD-7HP from Sigma-Aldrich. The main physical characteristics of the resin are shown in Table 1. The resin beads were first soaked in $100 \%$ ethanol for $30 \mathrm{~min}$ at room temperature. They were then washed twice with MilliQ water in order to remove the salts that come with the shipped product (data from supplier, Sigma-Aldrich), filtered and left to dry.

In Table 1, the porosity was obtained in $\mathrm{mL} \mathrm{g}^{-1}$ dry from the supplier and converted to $\mathrm{mL} \mathrm{mL}^{-1}$. This was achieved by dividing the specific void volume $\left(\varepsilon_{p}\right)$ by the total particle volume (void + skeleton volume $\left.\left(1 / \rho_{\text {skel }}\right)\right)$. The term $\rho_{\text {skel }}$ corresponds to the resin skeleton density.

$$
\varepsilon_{p}(m L / m L)=\frac{\varepsilon_{p}\left(m L / g_{\text {dry }}\right)}{\varepsilon_{p}\left(m L / g_{\text {dry }}\right)+\frac{1}{\rho_{\text {skel }}(g / m L)}}
$$

In Table 1, the wet dry ${ }^{-1}$ mass ratio was obtained considering that the moisture holding capacity of the resins is $65 \%$ (data from supplier). The bulk density ( $\rho_{\text {bulk }}$ ) was calculated from the resin wet density $\left(\rho_{\text {wet }}\right)$, obtained from the supplier, and by considering that the external porosity $(\varepsilon)$ has a typical value of $0.4,{ }^{25}$

$$
\rho_{\text {bulk }}=\rho_{\text {wet }} \cdot(1-\varepsilon)
$$

\section{Sampling and quantification of glucose and biomass}

Samples from the bioreactor were taken at regular sampling times for the analysis of biomass and glucose. Biomass concentration was determined by measuring $\mathrm{OD}_{600}$. The $\mathrm{OD}$ values were converted to biomass dry weight using a calibration procedure. HPLC analysis was performed in a JASCO system using a refractive index detector (RI- 2031). The supernatants of the samples were analyzed using an Aminex HPX-87 $\mathrm{H}$ column from Bio-Rad, which was kept at $60^{\circ} \mathrm{C}$ and $10 \mathrm{mmol} \mathrm{L}^{-1} \mathrm{H}_{2} \mathrm{SO}_{4}$ was used as mobile phase with a flow rate of $0.5 \mathrm{~mL} \mathrm{~min}{ }^{-1}$. Quantitative analysis of glucose was performed by injecting standards with known concentrations. The calibration curve was calculated using the peak areas of the RI detector for glucose.

\section{Extraction of metabolites from the medium}

For the quantification of $p$-coumaric acid and resveratrol, metabolite extracts from the cultivation broth were prepared according to Kallscheuer et al. ${ }^{12}$ with some modifications. Extracellular and broth (intracellular + extracellular) polyphenols concentrations were measured using the supernatant, after centrifugation, and total broth, respectively. Metabolite extracts were prepared by mixing $1 \mathrm{~mL}$ of the samples, acidified at $\mathrm{pH} 2$ with $6 \mathrm{~mol} \mathrm{~L}^{-1}$ $\mathrm{HCl}$, with $1 \mathrm{~mL}$ ethyl acetate and vigorously shaking for $2 \mathrm{~min}$, in order to permeabilize the cells. ${ }^{26}$ The suspension was centrifuged for $5 \mathrm{~min}$ at $8000 \mathrm{~g}$ and the ethyl acetate layer $(600 \mu \mathrm{L})$ was transferred to a solvent-resistant micro tube (Eppendorf, Germany). After evaporation of the ethyl acetate overnight, dried extracts were resuspended in $100 \mu \mathrm{L}$ of acetonitrile and directly used for UHPLC analysis.

\section{Extraction of metabolites from resins}

At the end of the fermentation, the resin was separated from the broth by sedimentation and was first washed with a $10 \%$ ethanol/water volume equivalent to 5 -fold of wet bead weight (direct adsorption) or 5 column volumes (external adsorption). The amount of resveratrol extracted, after this washing step, was quantified and found to be negligible. In the end, the resin was eluted with $70 \%$ ethanol/water (10 column volumes for the external adsorption and 10 times the wet bead weight for direct adsorption). With this ethanol content, no binding of resveratrol is expected to occur (Silva et al. (unpublished)). Although not specifically for this molecule, the same conclusions regarding similar polyphenols were obtained by Monsanto et al. ${ }^{27}$ and David Mendez et $a l^{28}$ Both fractions, from the washing and elution steps, were used for UHPLC analysis.

\section{Stilbenes determination - fermentation experiments}

Stilbenes (resveratrol and $p$-coumaric acid) in extracted samples were quantified by using an UHPLC Shimadzu system using a diode array detector SPD-M20A. Separation was carried out with a Kinetex $1.7 \mathrm{u}$ C18 $100 \AA$ pore size column $(50 \mathrm{~mm}$ by $2.1 \mathrm{~mm}$ internal diameter; Phenomenex) at $50{ }^{\circ} \mathrm{C}$. For elution, $0.1 \%$ acetic acid (solvent $A$ ) and acetonitrile supplemented with $0.1 \%$ acetic acid (solvent B) were applied as the mobile phases at a flow rate of

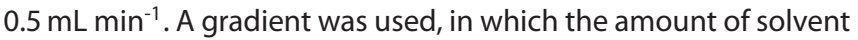
B was increased stepwise: $\min 0$ to $6: 10 \%$ to $30 \%$, $\min 6$ to $7: 30 \%$ to $50 \%$, $\min 7$ to $8: 50 \%$ to $100 \%$ and $\min 8$ to $8.5: 100 \%$ to $10 \% .^{12}$ 

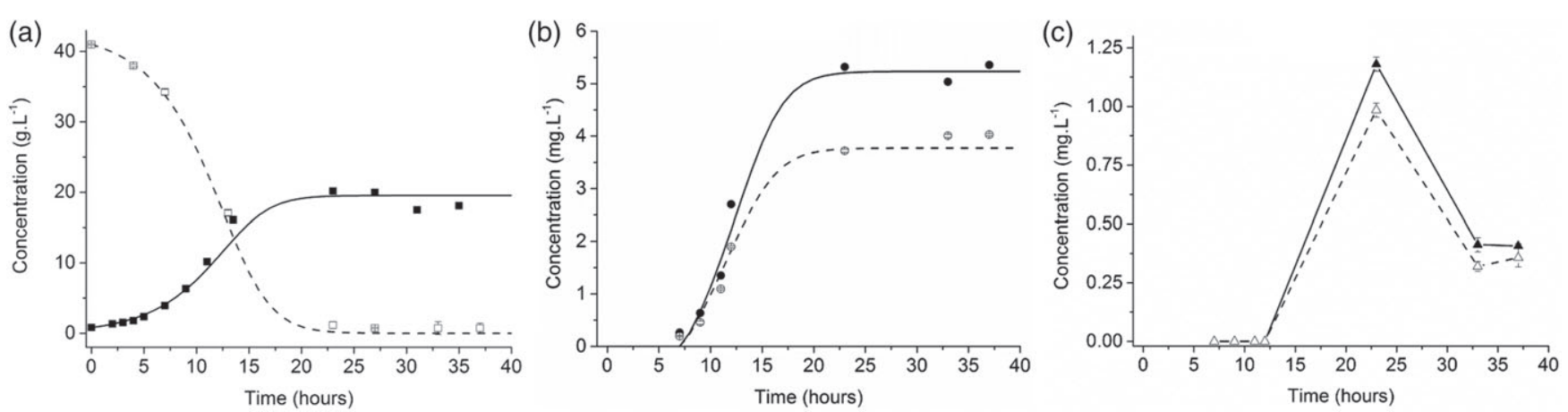

Figure 2. Cultivation profile of C. glutamicum DelAro, ${ }^{4}$ including biomass concentration (dwt) ( $\square$ ) and glucose consumption profile $(\square)$ in batch experiments (a); the broth $(\mathbf{\bullet})$ and extracellular $(\bigcirc)$ resveratrol concentrations $(b)$; the broth $(\mathbf{\Delta})$ and extracellular $(\triangle)$ p-coumaric acid concentrations $(\triangle)$ (c). Data are presented as average and standard deviation of two independent experiments (if no error bars are visible, the standard deviations were too small to be displayed).

Area values were linear up to metabolite concentrations of at least $250 \mathrm{mg} \mathrm{L}^{-1}$. The detection of $p$-coumaric acid was performed at $277 \mathrm{~nm}$ and that of resveratrol at $333 \mathrm{~nm}$.

\section{Stilbenes determination - adsorption experiments}

For the experiments involving the resin adsorption isotherm determination and adsorption kinetics, a different UHPLC method was used. In this case, the quantification of $p$-coumaric acid and resveratrol was carried out by UHPLC (Ultimate 3000, Thermo Scientific, USA) in a C18 column (Acquity UPLC HSS column, $1.8 \mu \mathrm{m}, 2.1 \mathrm{~mm}$ $\times 100 \mathrm{~mm}$ Waters, Milford, USA). Mobile phase A consisted of $10 \%$ formic acid in Milli-Q water and mobile phase B of $10 \%$ formic acid in acetonitrile. Every run was performed in isocratic mode, with the mobile phase containing $33.5 \%$ of $B$ and $66.5 \%$ of $A$ and flowing at $0.30 \mathrm{~mL} \mathrm{~min}{ }^{-1}$. The detection of $p$-coumaric acid was performed at $340 \mathrm{~nm}$ and that of resveratrol at $304 \mathrm{~nm}$.

\section{Error calculation - adsorption experiments}

For all the batch experiments performed, the uncertainty associated with the measurements and the regressed parameters was obtained as described in Sevillano et al. ${ }^{28}$ The standard deviation of the measurements was calculated according to the theory of error propagation. ${ }^{29}$ The standard deviation of the estimated parameters was obtained by taking the parameter covariance matrix as the inverse of the Fisher information matrix:

$$
F I M=\sum_{i=1}^{N} J^{T} \frac{1}{\sigma_{i}} J
$$

where $\sigma_{i}$ is the standard deviation of the ith observation and $J$ is the Jacobian matrix of the least squares regression function.

\section{RESULTS AND DISCUSSION}

\section{Batch production of resveratrol by $C$. glutamicum}

During the cultivation of $C$. glutamicum in the bioreactor, in batch mode, a maximum biomass concentration of $18 \mathrm{~g} \mathrm{~L}^{-1}$ was obtained after $23 \mathrm{~h}$ of growth (Fig. 2(a)). Looking at the substrate consumption profile, it was possible to observe that glucose is completely depleted from the medium, suggesting that cell growth starts to decelerate due to limitation of this substrate. Under these conditions $Y_{X / g l u}$ was 0.46 (g cell dry weight per g glucose), which is in agreement with data already published for this bacteria. ${ }^{30}$
It was observed that an increase in the resveratrol titer occurred only during the exponential growth and no further increase was achieved during the stationary phase. After $23 \mathrm{~h}$ of growth, a total resveratrol concentration of $5.3 \mathrm{mg} \mathrm{L}^{-1}$ was detected (Fig. 2(b)). In contrast, the level of extracellular resveratrol was $4 \mathrm{mg} \mathrm{L}^{-1}$. In $C$. glutamicum, malonyl-CoA is exclusively used for the production of fatty acids. Typically, malonyl-CoA synthesis strongly decreases in the stationary phase (as fatty acids are only required for biomass production), which explains why the production of resveratrol stops at this stage.

Concerning $p$-coumaric acid (Fig. 2(c)), the maximum concentration observed in the culture medium was $1.2 \mathrm{mg} \mathrm{L}^{-1}$ and around $1 \mathrm{mg} \mathrm{L}^{-1}$ in the supernatant. The $p$-coumaric acid accumulation only in the stationary phase is a clear hint that it is the rate-limiting metabolite during production. ${ }^{12}$

In fact, the titers of resveratrol produced by C. glutamicum are lower in direct comparison with other already published microbial production strains, ${ }^{2,10}$ but the use of this strain as a platform for polyphenol production is highly appealing for the reasons explained in the Introduction. Further research and development of this strain, aiming at increasing the resveratrol titers, may result in a good platform for industrial resveratrol production. However, the level of measured resveratrol may not be a true reflection of the amount of resveratrol produced, as an indeterminate amount is probably being degraded by oxygen and other factors, such as $\mathrm{pH}$, temperature and light. 20,31,32 It cannot be ignored that resveratrol tends to oxidize in the aerated fermenter and the high oxygen levels needed for cell growth have a strong negative impact on resveratrol production. ${ }^{13}$ Therefore, product removal strategies such as direct and external adsorption can be very promising strategies for adsorbing and storing the secreted resveratrol and simultaneously purifying polyphenol compounds from the fermentation stream.

\section{Adsorption isotherms of $p$-coumaric acid and resveratrol onto the Amberlite XAD-7HP resin}

The choice of using a hydrophobic resin, such as the XAD-7HP, for the continuous removal of resveratrol was twofold. First of all, given that resveratrol is highly hydrophobic $(\log P \text { of } 3.4)^{33}$ this resin was expected to strongly adsorb this polyphenol. Similar results were obtained for many antioxidants like $\alpha$-tocopherol and $\alpha$-tocopheryl acetate, which share several common characteristics with resveratrol. ${ }^{34}$ More recently, Vuong et al. also described the resveratrol production in Vitis vinifera $L$. cell suspension cultures with in situ adsorption, using XAD-7HP as adsorbent. ${ }^{3}$ The second 

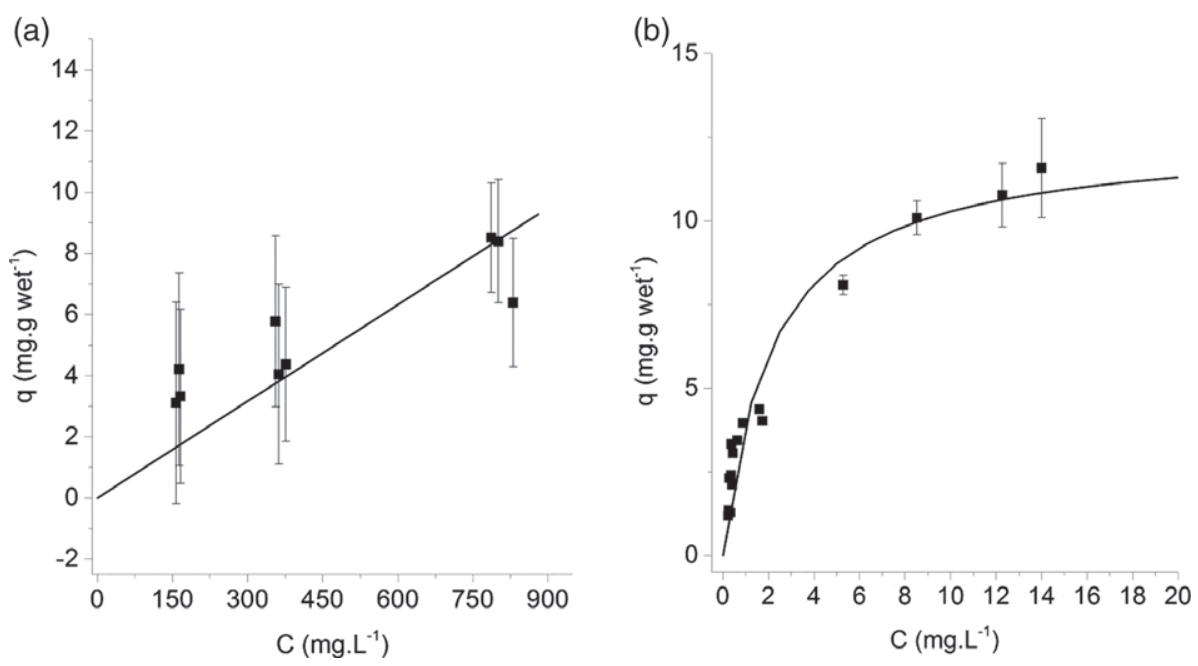

Figure 3. Adsorption isotherms of $p$-coumaric acid (a) and of resveratrol (b) onto the Amberlite XAD-7HP resin (equilibrium adsorption capacity (mg $\left.\mathrm{g}^{-1} \mathrm{wet}\right)$ is plotted against equilibrium liquid concentration $\left(\mathrm{mg} \mathrm{L}^{-1}\right)$. Data are presented as average and standard error.

Table 2. Regressed isotherm parameters for $p$-coumaric acid and resveratrol onto the Amberlite XAD 7HP resin, using MilliQ water as solvent. The linear isotherm model was fitted to the experimental data of $p$-coumaric acid and the Langmuir isotherm model was fitted to the experimental data of resveratrol

\begin{tabular}{|c|c|c|}
\hline & \multicolumn{2}{|c|}{ Amberlite XAD-7HP } \\
\hline & $p$-coumaric acid & resveratrol \\
\hline $\mathrm{Q}_{\max }\left(\mathrm{mg} \mathrm{g}\right.$ wet $\left.^{-1}\right)$ & - & $12.5 \pm 0.3$ \\
\hline $\mathrm{K}_{\mathrm{L}}\left(\mathrm{L} \mathrm{mg}^{-1}\right)$ & - & $0.46 \pm 0.02$ \\
\hline$K\left(\operatorname{Lg~wet}^{-1}\right)$ & $0.011 \pm 0.001$ & - \\
\hline
\end{tabular}

reason for the selection of this resin had in consideration that since p-coumaric acid is mostly ionized at pH 7.0, its affinity towards the resin is expected to be much lower than for resveratrol. This is of crucial importance, as $p$-coumaric acid is a precursor for the synthesis of resveratrol.

The adsorption isotherm determined for $p$-coumaric acid is indicated in Fig. 3(a), where a linear model was used to fit the experimental data. On Fig. 3(b), the adsorption isotherm of resveratrol is shown. The Langmuir model was used in this case, since the resin started to show some saturation for larger concentrations in the liquid phase. This model was also chosen due to its capacity for describing the physical adsorption of neutral molecules onto adsorption sites. $^{27}$

From the analysis of Fig. 3 it is possible to observe that, as expected, the adsorption of $p$-coumaric acid is much weaker than that of resveratrol. The reasons for this lie in the fact that, as previously mentioned, resveratrol is more hydrophobic than $p$-coumaric acid. Moreover, since it is a carboxylic acid, $p$-coumaric acid is negatively charged at pH 7.0, making it even more polar and with higher affinity for the aqueous phase.

In Table 2, the regressed parameters for the linear adsorption isotherm of $p$-coumaric acid and the Langmuir adsorption isotherm of resveratrol are indicated.

\section{Resveratrol production by C. glutamicum with external and direct adsorption}

The application of product removal techniques to a biotechnological process may bring benefits such as avoiding or reducing inhibition or toxicity, product stabilization and facilitation of further downstream processing..$^{35}$ Advantages of solid resins, in particular, compared with traditional organic solvents are insolubility in the aqueous phase, no volatilization, high biocompatibility and reduced environmental hazard. ${ }^{36}$

Figure 4(a) (filled lines) shows the C. glutamicum growth profile and substrate consumption in batch cultures with external adsorption strategy, using XAD-7HP as adsorbent.

Comparing the growth profiles under this condition with batch without adsorption (Fig. 2(a)), it was clearly confirmed that the viability of the cells is not affected by the presence of the resins, i.e. neither adsorption of essential nutrients to the resin nor counter-ion release into the medium are problematic for the external adsorption strategy. The results of Fig. 4(a) evidence this behavior, since the polymer appeared to have no affinity for glucose, as the substrate consumption profile was not affected. Regarding the production of resveratrol, the results obtained suggest that its kinetic profile is also similar when compared with batch experiments without continuous product removal (Fig. 4(b)). Nonetheless, lower amounts were obtained when using the integrated strategies. While for the batch experiments without product removal $5.36 \mathrm{mg} \mathrm{L}^{-1}$ of resveratrol were obtained, the value dropped to $2.2 \mathrm{mg} \mathrm{L}^{-1}$ for the direct adsorption scenario and to $3.6 \mathrm{mg} \mathrm{L}^{-1}$ for the case of external adsorption (Table 3 ).

One of the key points also worth noticing is that the ratio of the extracellular resveratrol (amount in the liquid phase plus the amount adsorbed) compared with the total amount, increased from $70 \%$, when no product removal was performed, to $90 \%$ (direct adsorption) and 95\% (external adsorption), as indicated in Table 3. This suggests that the external adsorption strategy might in fact promote product excretion from the cells, as desired. Supposing that only the resveratrol present in the liquid or in the resin could be recovered (no cell breaking step), the scenario without adsorption would provide $4.03 \mathrm{mg} \mathrm{L}^{-1}$, compared with $1.96 \mathrm{mg} \mathrm{L}^{-1}$ from the direct adsorption and $3.42 \mathrm{mg} \mathrm{L}^{-1}$ from the external adsorption scenario. When performing this analysis, the 'recoverable' resveratrol in the external adsorption scenario is only $15 \%$ lower than in the original batch situation, where no recovery is present.

When using a continuous product removal strategy such as the ones proposed in this work, two behaviors are expected. First, 
(a)

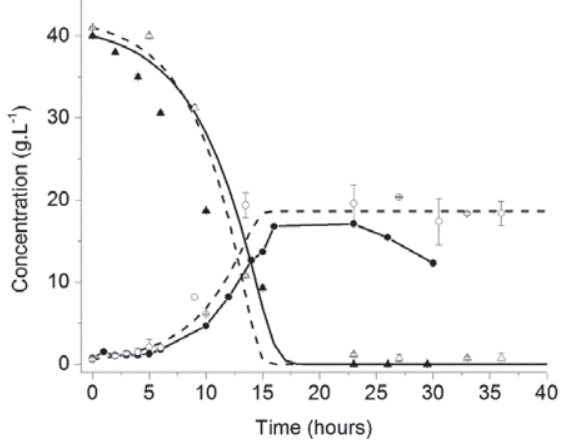

(b)

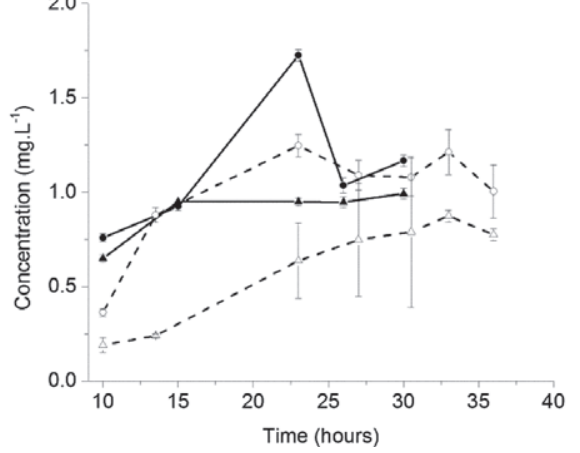

(c)

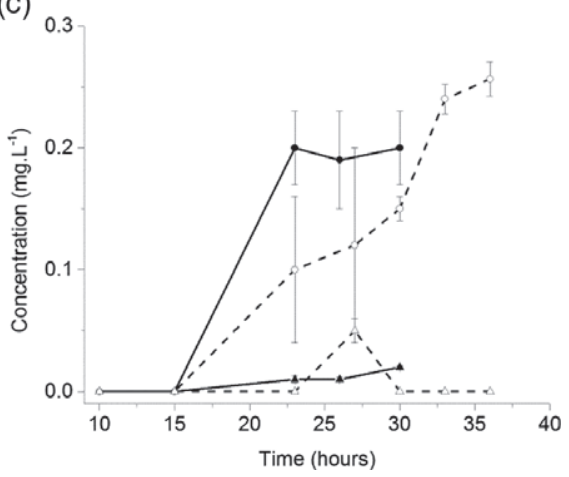

Figure 4. Cultivation profile for C. glutamicum DelAro ${ }^{4}$ for the external adsorption (filled lines and symbols) and for the direct adsorption scenarios (dashed lines and empty symbols). (a) Biomass concentration (dwt) (circles) and glucose consumption profiles (triangles); the total produced resveratrol is depicted in (b) (circles), together with the extracellular profiles (triangles); the total produced p-coumaric acid is depicted in (c) (circles), together with the extracellular profiles (triangles). Data are presented as average and standard deviation of two independent experiments (If no error bars are visible, the standard deviations were too small to be displayed).

\begin{tabular}{|c|c|c|c|}
\hline Resveratrol & Batch & $\begin{array}{c}\text { Direct } \\
\text { adsorption }\end{array}$ & $\begin{array}{c}\text { External } \\
\text { adsorption }\end{array}$ \\
\hline Extracellular $\left(\mathrm{mg} \mathrm{L}^{-1}\right)$ & $4.03 \pm 0.02$ & $0.76 \pm 0.03$ & $0.99 \pm 0.03$ \\
\hline $\begin{array}{l}\text { Broth (extracellu- } \\
\text { lar }+ \text { intracellular) } \\
\quad\left(\mathrm{mg} \mathrm{L}^{-1}\right)\end{array}$ & $5.36 \pm 0.01$ & $1.00 \pm 0.14$ & $1.17 \pm 0.03$ \\
\hline $\operatorname{Resin}\left(\mathrm{mg} \mathrm{L}^{-1}\right)$ & - & $1.20 \pm 0.02$ & $2.43 \pm 0.04$ \\
\hline $\begin{array}{l}\text { Ratio extracellular } \\
\text { total }^{-1} \\
\left(\frac{\text { Extracellular+Resin }}{\text { Broth+Resin }}\right)\end{array}$ & 0.75 & 0.90 & 0.95 \\
\hline
\end{tabular}

there might be an increase in production due to the reduction in product toxicity (not studied in this work). Second, by continuously removing resveratrol, the product will tend to accumulate outside the cell, mostly inside the resin beads (Fig. 5).

In Fig. 5 (left), the proposed situation of the C. glutamicum cells for the batch experiment scenario is depicted. At the end of the cell growth phase, an equilibrium between the inside cell concentration and the external concentration is obtained. Nonetheless, being highly lipophilic, it is expected that resveratrol is highly partitioned towards the cell membrane. Considering that the intracellular volume is around $2 \%$ of the total broth volume and that the intracellular resveratrol concentration is $1.34 \mathrm{mg}$ per $\mathrm{L}$ broth, the local concentration inside the cells should be in the range of $60 \mathrm{~g} \mathrm{~L}^{-1}$, probably mostly in the membrane.

The equivalent situation for the continuous removal strategy is depicted in Fig. 5 on the right. The figure assumes that a 'picture' was taken during the interval when resveratrol is being synthesized and, at the same time, the molecule is being adsorbed onto the XAD-7HP resin (steady-state is also assumed). It is also implied that the limiting step for mass transfer is membrane diffusion. Now, because the extracellular concentration becomes close to zero (adsorption occurs at a fast rate), the intracellular content of resveratrol becomes much lower than in the batch scenario. That will result in the accumulation of the molecule not inside the cell, but mostly inside the resin beads, from which it can be eluted with a water/ethanol mixture (ethanol rich).

While the explanations provided can explain why the extracellular/intracellular ratio of resveratrol increased for the continuous removal scenarios, it does not explain the decrease in total production. At least two reasons may be given. One of them has to do with the decrease in precursor availability due to the presence of the adsorbent. As shown previously, although the adsorption of p-coumaric acid onto the XAD-7HP is weak (Fig. 2), it is probably not negligible. As depicted in Fig. 4(c), the level of $p$-coumaric acid detected in the culture medium when using either the external or the direct product adsorption strategies is roughly 5.9-fold lower than the one detected when no adsorption was applied (Fig. 2(c)). The other one is related to the concentration levels attained during the performed experiments. Having such low values (in the range of $0.25-5 \mathrm{mg} \mathrm{L}^{-1}$ ), might make the comparison between the different scenarios more difficult, especially knowing that oxidation and isomerization reactions of resveratrol might occur. ${ }^{13}$ Using strains able to achieve higher titers might then lead to a better understanding of the possible improvements given by the continuous product removal strategy.

The key message to be conveyed with this work is that despite having achieved lower titers, the integrated product removal strategy showed potential to be applied in a batch industrial process. Not only the downstream process has the capacity of being integrated with the upstream batch fermentation, possibly leading to energy cost and waste reduction, but it also leads to its own simplification. As this work suggests, not only $70 \%$, but close to $95 \%$ of the total produced resveratrol may be present outside the cells, avoiding the need of a cell lysis step and reinforcing the possible energy cost and waste reduction previously mentioned.

\section{CONCLUSIONS}

This work investigated the possible advantages of continuously extracting resveratrol as it was produced by $C$. glutamicum in a batch fermentation process. In the batch experiments without integrated recovery, a total titer of $5.36 \mathrm{mg}$ resveratrol $\mathrm{L}^{-1}$ was obtained. Although it was the largest titer obtained among all the experiments performed, the amount of resveratrol inside the cells was still substantial ( $25 \%$ of the total content). For the continuous removal experiments, titers of $2.2 \mathrm{mg} \mathrm{L}^{-1}$ and $3.6 \mathrm{mg} \mathrm{L}^{-1}$ were obtained for the direct and external adsorption, respectively. Despite the lower titers obtained in both situations, which might be associated with the adsorption of the precursor of resveratrol, $p$-coumaric acid, the ratio of the extracellular plus adsorbed to the total resveratrol produced, was increased for the scenarios 

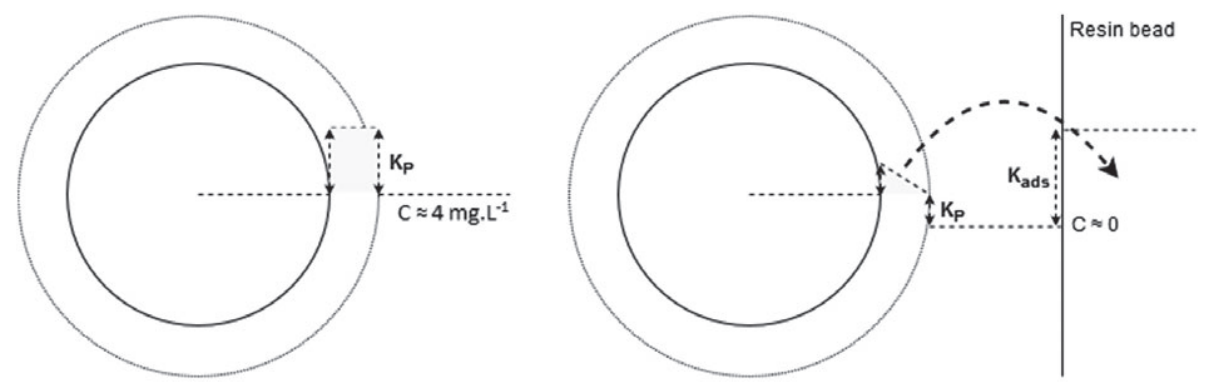

Figure 5. Comparison, at the cellular level, between the concentration profiles of resveratrol in the batch scenario (left) and the in situ product removal scenario (right). When no resin is present, the product concentration inside and outside the cells tend to equalize. Nonetheless, due to the high lipophilicity of resveratrol (expressed by its $K_{p}$ partition value), a higher concentration is expected in the membrane and, as a result, inside the cells. If adsorbent is put into contact with the cells, while resveratrol is being synthesized inside the cell and diffusing to the liquid (passive diffusion in the membrane is assumed to be the limiting step), it is also being removed from that same liquid phase. This leads to a reduction of this polyphenol concentration inside the cell and its shift to the hydrophobic resin beads, for which it has high affinity.

where the XAD-7HP resin was used $(90 \%$ of the total for the direct adsorption and $95 \%$ of the total for the external adsorption). This suggests that, even though lower titers were obtained for the continuous product removal strategies, the desired product could be almost totally recovered outside the cells. For that reason, a possible downstream at a larger scale could potentially avoid using a cell lysis step, which would increase not only costs but also complex the subsequent downstream process steps. The proposed integrated strategies, which might still be improved by manipulating the ratio of solid phase (resin) to liquid ratio, can provide not only a simpler recovery and purification process, but also avoid potential problems with product toxicity to the cells (in case the polyphenol reaches higher concentrations in the medium).

Future work may, however, unveil a potential increase in productivity. Two strategies should be addressed to try this. One consists of decreasing the amount of $p$-coumaric acid adsorption by the resin. This would certainty lead to a strong increase in the total amount of resveratrol produced per batch volume. The second strategy proposed would consist of forming the batch fermentation into a continuous production process. The in situ product removal strategy should allow a continuous or fed-batch fermentation operation, without falling into toxicity limitations due to an excess of resveratrol in the system and protecting the product from oxidative degradation. These may lead to an increase in the overall production rate per unit time when compared with a batch operation.

\section{ACKNOWLEDGEMENTS}

We would like to thank the European Union Framework Program 7 'BacHBerry' (www.bachberry.eu), Project No. FP7- 613793 for financial support, the Portuguese Foundation for Science and Technology (FCT) under the scope of the strategic funding of UID/BIO/04469/2013 unit, COMPETE 2020 (POCl-010145-FEDER-006684) and BioTecNorte operation (NORTE-01-0145FEDER-000004) funded by the European Regional Development Fund under the scope of Norte2020 - Programa Operacional Regional do Norte.

\section{REFERENCES}

1 Vidavalur R, Otani H, Singal PK and Maulik N, Significance of wine and resveratrol in cardiovascular disease: French paradox revisited. Exp Clin Cardiol 1:217-225 (2006).

2 Li M, Kildegaard KR, Chen Y, Rodriguez A, Borodina I and Nielsen J, De novo production of resveratrol from glucose or ethanol by engineered Saccharomyces cerevisiae. Metab Eng 32:1 - 11 (2015).
3 Vuong TV, Franco C and Zhang W, Treatment strategies for high resveratrol induction in Vitis vinifera L. cell suspension culture. Biotechnol Reports 1-2:15-21 (2014).

4 Donnez $D$, Jeandet $P$, Clément $C$ and Courot $E$, Bioproduction of resveratrol and stilbene derivatives by plant cells and microorganisms. Trends Biotechnol 27:706-713 (2009).

5 Marienhagen $\mathrm{J}$ and Bott $\mathrm{M}$, Metabolic engineering of microorganisms for the synthesis of plant natural products. J Biotechnol 163:166-178 (2013).

6 Pandey RP, Parajuli P, Koffas MAG and Sohng JK, Microbial production of natural and non-natural flavonoids: pathway engineering, directed evolution and systems/synthetic biology. Biotechnol Adv 34:634-662 (2015).

7 van Summeren-Wesenhagen PV and Marienhagen J, Metabolic engineering of Escherichia coli for the synthesis of the plant polyphenol pinosylvin. Appl Environ Microbiol 81:840-849 (2015).

8 Beekwilder J, Wolswinkel R, Jonker H, Hall R, De Rie Vos CH and Bovy A, Production of resveratrol in recombinant microorganisms. Appl Environ Microbiol 72:5670-5672 (2006).

9 Vos T, de la Torre Cortés P, van Gulik WM, Pronk JT and Daran-Lapujade $P$, Growth-rate dependency of de novo resveratrol production in chemostat cultures of an engineered Saccharomyces cerevisiae strain. Microbiol Cell Factory 14:133 (2015).

10 Camacho-Zaragoza JM, Hernández-Chávez G, Moreno-Avitia F, Ramírez-Iñiguez R, Martínez A, Bolívar $F$ et al., Engineering of a microbial coculture of Escherichia coli strains for the biosynthesis of resveratrol. Microbiol Cell Factory 15:163 (2016).

11 Takors R, Bathe B, Rieping M, Hans S, Kelle R and Huthmacher $\mathrm{K}$, Systems biology for industrial strains and fermentation processes - Example: amino acids. J Biotechnol 129:181-190 (2007).

12 Kallscheuer N, Vogt M, Stenzel A, Gätgens J, Bott M and Marienhagen J, Construction of a Corynebacterium glutamicum platform strain for the production of stilbenes and (2S)-flavanones. Metab Eng 38:47-55 (2016).

13 Braga A, Oliveira J, Silva R, Ferreira P, Rocha I, Kallscheuer N et al., Impact of the cultivation strategy on resveratrol production from glucose in engineered Corynebacterium glutamicum. J Biotechnol 265:70-75 (2017).

14 Eikmanns BJ, Metzger M, Reinscheid D, Kircher M and Sahm H, Amplification of three threonine biosynthesis genes in Corynebacterium glutamicum and its influence on carbon flux in different strains. Appl Microbiol Biotechnol 34:617-622 (1991).

15 Liu YB, Long MX, Yin YJ, Si MR, Zhang L, Lu ZQ et al., Physiological roles of mycothiol in detoxification and tolerance to multiple poisonous chemicals in Corynebacterium glutamicum. Arch Microbiol 195:419-429 (2013).

16 Kallscheuer N, Vogt M, Kappelmann J, Krumbach K, Noack S, Bott $\mathrm{M}$ et al., Identification of the phd gene cluster responsible for phenylpropanoid utilization in Corynebacterium glutamicum. Appl Microbiol Biotechnol 100:1871 - 1881 (2016).

17 van Summeren-Wesenhagen PV and Marienhagen J, Putting bugs to the blush: metabolic engineering for phenylpropanoid-derived products in microorganisms. Bioengineered 4:355-362 (2013). 
18 Lim CG, Fowler ZL, Hueller T, Schaffer S and Koffas MAG, High-yield resveratrol production in engineered Escherichia coli. Appl Environ Microbiol 77:3451-3460 (2011).

19 Wu J, Liu P, Fan Y, Bao H, Du G, Zhou J and Chen J, Multivariate modular metabolic engineering of Escherichia coli to produce resveratrol from l-tyrosine. J Biotechnol 167:404-411 (2013).

20 Zupančič Š, Lavrič Z and Kristl J, Stability and solubility of trans-resveratrol are strongly influenced by $\mathrm{pH}$ and temperature. Eur J Pharm Biopharm 93:196-204 (2015).

21 Afonso MS, Ferreira S, Domingues FC and Silva F, Resveratrol production in bioreactor: assessment of cell physiological states and plasmid segregational stability. Biotechnol Rep 5:7-13 (2015).

22 Hwang $\mathrm{D}$ and Lim Y-H, Resveratrol antibacterial activity against Escherichia coli is mediated by Z-ring formation inhibition via suppression of FtsZ expression. Sci Rep 5:1-10 (2015).

23 Woodley J, Bisschops M, Straath of A and Ottens M, Perspective future directions for in situ product removal (ISPR). J Chem Technol Biotechnol 83:121-123 (2008)

24 Keilhauer C, Eggeling L and Sahm H, Isoleucine synthesis in Corynebacterium glutamicum: molecular analysis of the ilvB-ilvN-ilvC operon. $J$ Bacteriol 175:5595-5603 (1993).

25 Giorgio C and Jungbauer A, Protein Chromatography: Process Development and Scale-Up. Wiley-VCH Verlag GmbH \& Co., KGaA (2010).

26 Kumar A and Awasthi A, Bioseparation engineering : a comprehensive DSP volumen. I.K. International Publishing, New Delhi (2009).

27 Monsanto M, Mestrom R, Zondervan E, Bongers P and Meuldijk J, Solvent swing adsorption for the recovery of polyphenols from black tea. Ind Eng Chem Res 54:434-442 (2015).
28 Sevillano DM, Jankowiak L, Van Gaalen TLT, Van der Wielen LAM, Hooshyar N, Van der Goot A et al., Mechanism of isoflavone adsorption from okara extracts onto food-grade resins. Ind Eng Chem Res 53:15245-15252 (2014).

29 Skoog DA, Holler FJ and Crouch SR, Principles of Instrumental Analysis. Cengage Learning (2017).

30 Buchholz J, Schwentner A, Brunnenkan B, Gabris C, Grimm S, Gerstmeir $R$ et al., Platform engineering of corynebacterium glutamicum with reduced pyruvate dehydrogenase complex activity for improved production of I-lysine, I-valine, and 2-ketoisovalerate. Appl Environ Microbiol 79:5566-5575 (2013).

31 Trošt K, Golc-Wondra A and Prošek M, Degradation of polyphenolic antioxidants in blueberry nectar aseptically filled in PET. Acta Chim Slov 56:494-502 (2009).

32 Lucas-Abellán C, Fortea I, López-Nicolás JM and Núñez-Delicado $\mathrm{E}$ Cyclodextrins as resveratrol carrier system. Food Chem 104:39-44 (2007).

33 Swain M, [Online]. Available: https://chemicalize.com/ [02 December 2017].

34 Ballesteros E, Gallego M and Valca M, Continuous-flow determination of natural and synthetic antioxidants in foods by gas chromatography. Anal Chim Acta 359:47-55 (1998).

35 Hua D, Ma C, Song L, Lin S, Zhang Z, Deng Z et al., Enhanced vanillin production from ferulic acid using adsorbent resin. Appl Microbiol Biotechnol 74:783-790 (2007).

36 Guo JL, Mu XQ and Xu Y, Integration of newly isolated biocatalyst and resin-based in situ product removal technique for the asymmetric synthesis of (R)-methyl mandelate. Bioprocess Biosyst Eng 33:797-804 (2010) 